\title{
Sistem Pertanian Konservasi Pola Agroforestri dan Hubungannya dengan Tingkat Erosi di Wilayah Sub-DAS Wuno, Das Palu, Sulawesi Tengah
}

\author{
N. Naharuddin \\ Departemen Kehutanan, Universitas Tadulako, Palu, Indonesia
}

Artikel Masuk : 21 Juni 2018

Artikel Diterima : 14 November 2018

Tersedia Online : 31 Desember 2018

\begin{abstract}
Abstrak: Wilayah hulu Sub-DAS Wuno di DAS Palu mengalami eksploitasi tata guna lahan besar-besaran yang berdampak pada peningkatan erosi. Salah satu cara menekan laju erosi adalah dengan menerapkan sistem pertanian konservasi. Penelitian ini bertujuan untuk mengetahui sistem pertanian konservasi pola agroforestri berbasis sistem informasi geografis serta tingkat erosi pada sistem pertanian konservasi pola agroforestri yang diterapkan oleh masyarakat di Sub-DAS Wuno, DAS Palu Kabupaten Sigi, Sulawesi Tengah. Metode yang digunakan adalah interpretasi citra dan survei lapangan untuk memperoleh data secara langsung terhadap suatu objek menggunakan GPS. Hasil penelitian menunjukkan bahwa terdapat empat pola agroforestri di Sub-DAS Wuno yaitu trees along border, alternate rows, alley cropping and random mixture. Tingkat erosi tertinggi adalah pola agroforestri alley cropping sebesar 5,17 g/ha dan terkecil adalah trees along border sebesar 0,47 g/ha dari total curah hujan sebesar 493,6 mm. Tutupan kanopi dari pola agroforestri mempengaruhi jumlah erosi yang terjadi.
\end{abstract}

Kata Kunci: daerah aliran sungai; erosi; konservasi

\begin{abstract}
The upstream part of Wuno Subwatershed in Palu Watershed experiences massive land use change exploitation, causing erosion impact increasingly. An alternative way for reduce the erosion level is by applying conservation farming system. This research aims to examine the conservation farming system with GIS-based agroforestry pattern and its effects to the erosion level reduction perceived by the community living in the Wuno Subwatershed. The method used is image interpretation and field survey to obtain data directly on an object using GPS. The results show that there are four agroforestry patterns in Wuno subwatershed, that is, trees along border, alternate rows, alley cropping and random mixture. The highest erosion level shown by the alley cropping pattern at 5.17 grams/ha and the lowest is trees along border at 0.47 grams/ha, all compared to the total rainfall level of $493.6 \mathrm{~mm}$. The canopy cover of the agroforestry pattern influences the erosion level occurs.
\end{abstract}

Keywords: conservation; erosion; watershed

\footnotetext{
${ }^{1}$ Korespondensi Penulis: Departemen Kehutanan, Universitas Tadulako, Palu, Indonesia email: nahar.pailing@gmail.com
} 


\section{Pendahuluan}

Perubahan tata guna lahan dari lahan hutan menjadi lahan pertanian telah banyak menimbulkan berbagai macam permasalahan. Permasalahan tersebut dapat dilihat dengan adanya perubahan lingkungan fisik dan sosial (As-Syakur, 2011). Hal tersebut juga terjadi di Sub-DAS (Daerah Aliran Sungai) Wuno yaitu dengan semakin tingginya laju angkutan sedimen (erosi) sebesar 22.811,15 ton/tahun (Tunas, 2008), serta berbagai macam permasalahan ekologis lain. Sebagai upaya pencarian solusi alternatif dalam penggunaan lahan yang efektif untuk menekan laju erosi, diperlukan formula berupa arahan sistem agroforestri dalam perbaikan lingkungan dan pembangunan wilayah di Sub-DAS Wuno.

Wilayah Sub-DAS Wuno telah dieksploitasi sehingga berdampak pada meningkatnya aliran permukaan dan erosi. Terbentuknya lahan kritis suatu DAS cenderung semakin meningkat karena laju erosi yang terjadi. Hal ini mengakibatkan permukaan lahan terganggu diantaranya unsur hara dan bahan organik tanah. Oleh karena itu, perilaku penggunaan lahan akan mempengaruhi kualitas air di DAS (Rahman, Purwanto, \& Suprihatin, 2014). Menurut Daswir (2010), salah satu cara menekan lahan degradasi adalah dengan menerapkan sistem pertanian konservasi. Lebih lanjut Atmojo (2008) menyatakan bahwa untuk meningkatkan efisiensi penggunaan lahan sekaligus menekan laju erosi, upaya konservasi dapat dilakukan secara terpadu antara pendekatan sipil teknik (mekanis) dan vegetatif seperti pembuatan teras dengan penanaman ganda, termasuk sistem agroforestri. Sistem pertanian konservasi pola agroforesti merupakan sistem pertanian yang dilakukan dengan cara menanam pepohonan secara tumpangsari dengan satu atau lebih jenis tanaman semusim (Hairiah, Sardjono, \& Sabarnurdin, 2003). Perubahan penutupan lahan akan memengaruhi penentuan kelas kerentanan lahan terhadap erosi.

Praktik pertanian konservasi dapat mencegah degradasi lahan dan hilangnya tanah produktif, menekan erosi, dan meningkatkan pertanian produktivitas dan pendapatan petani (Syam, 2003). Faktor jenis tutupan lahan merupakan salah satu instrumen pengelolaan kawasan dalam menjalankan fungsi pengendalian erosi (Naharuddin, 2017; Nuraida, Rachman, \& Baskoro, 2016). Sistem pertanian konservasi pola agroforestri adalah salah satu sistem pengelolaan lahan yang dapat ditawarkan untuk mengatasi masalah yang timbul akibat adanya alih guna lahan (Sardjono, Djogo, Arifin, \& Wijayanto, 2003).

Kerusakan hutan akibat tata guna lahan memengaruhi struktur dan komposisi vegetasi, yang selanjutnya dapat mengarah pada pembentukan lahan yang tidak produktif. Lahan yang mengalami degradasi ini menjadi semakin kritis karena erosi yang dipicu oleh aktivitas manusia yang ceroboh dan tidak bertanggung jawab (Sarminah, Karyati, Karmini, Simbolon, \& Tambunan, 2018). Curah hujan merupakan faktor penting yang berkontribusi terhadap erosi (Liu, Liu, \& Zhu, 2018).

Beberapa penelitian terdahulu yang terkait dengan sistem konservasi pola agroforestri lebih menekankan pada kondisi sifat fisik tanah, kimia tanah dan kandungan hara serta hubungannya dengan infiltrasi dan aliran permukaan (Darmayanti, 2012; Setyowati, 2008). Oleh karena itu, masalah yang belum terpecahkan adalah belum teridentifikasinya sistem pertanian konservasi pola agroforestri berbasis sistem informasi geografis (SIG) dan hubungannya dengan tingkat bahaya erosi pada setiap sistem pertanian konservasi pola agroforestri. Penelitian ini bertujuan untuk mengetahui sistem pertanian konservasi pola agroforestri berbasis SIG serta tingkat erosinya yang diterapkan di SubDAS Wuno, DAS Palu.

\section{Metode Penelitian}

\section{Tempat dan Waktu}

Penelitian ini dilaksanakan di Sub-DAS Wuno, DAS Palu yang terletak di Kecamatan Palolo Kabupaten Sigi, Sulawesi Tengah, berada pada titik koordinat $119^{\circ} 59^{\prime} 17.86^{\prime}$ BT dan 
$1^{\circ} 4^{\prime} 59.91$ 'LS dengan ketinggian 215 mdpl. Penelitian dilaksanakan dari bulan April sampai bulan September 2017.

\section{Metode Pengumpulan Data}

Alat yang digunakan adalah Global Positioning System (GPS) untuk mengambil titik koordinat, aplikasi Google Earth Pro Tahun 2017, clinometer sunto untuk mengukur kelerengan, seng plat untuk dinding pembatas plot erosi, ember ukuran 100 liter untuk penampung aliran permukaan dan erosi, corong plastik untuk pengumpulan sampel sedimen tanah terarosi, pipa air untuk penghubung aliran, timbangan analitik untuk tempat penimbangan sampel sedimen, kertas saring untuk menyaring endapan sedimen, oven untuk mengeringkan sampel sedimen, ambrometer untuk penakar curah hujan, kamera untuk dokumentasi. Bahan yang digunakan adalah peta Sub-DAS Wuno di DAS Palu, citra Google Earth Pro Tahun 2017, label gantung untuk mencatat kode sampel pada setiap petak pengamatan plot erosi.

\section{Metode Analisis Data}

\section{Identifikasi Sistem Pertanian Konservasi Pola Agroforestri}

Identifikasi sistem pertanian pola agroforestri dilakukan dengan beberapa cara, yaitu: (1) interpretasi citra dilakukan untuk mengkaji foto udara atau citra; (2) survei lapangan untuk memperoleh data secara langsung terhadap suatu objek di lapangan mengunakan GPS agar posisi koordinat UTM objek yang ada di lapangan dapat diketahui dengan mudah.

Proses pengumpulan data meliputi: (1) menentukan dan menetapkan lokasi yang ada pada Google Earth; (2) memotong citra Google Earth ke bentuk JPEG; (3) mengubah citra Google Earth dari JPEG ke format TIFF; (4) merektifikasi citra JPEG ke TIFF dengan cara georeferensi; (5) menumpangsusunkan peta citra Google Earth dengan peta administrasi kecamatan untuk menentukan tipologi spasial agar mitigasi dapat ditangani; (6) interpretasi; (7) ground check titik koordinat yang diambil pada Google Earth, dan menyesuaikan dengan kondisi yang ada di lapangan; (8) hasil survei diklasifikasi kembali untuk mencocokkan kondisi yang terjadi di lapangan; (9) finalisasi dengan membuat peta perbandingan pola agroforestri sesuai hasil yang didapatkan di lapangan; dan (10) membuat layout peta pola agroforestri.

\section{Erosi pada Sistem Pertanian Konservasi Pola Agroforestri}

Pengamatan erosi dilakukan dengan membuat petak erosi ukuran panjang $10 \mathrm{~m}$ dan $4 \mathrm{~m}$. Pengukuran dilakukan pada berbagai sistem pertanian konservasi pola agroforestri along border, alternate rows, alley cropping dan random mixture pada masing-masing kelerengan $25-40 \%$ (curam). Pengukuran dilakukan sebanyak 30 kali setiap pagi hari setelah terjadi hujan.

Pengamatan erosi tanah dilakukan setelah kejadian hujan kemudian ember diperiksa. Apabila airnya tersedia, maka air tersebut diaduk sampai rata lalu diambil sampelnya sebanyak $25 \mathrm{ml}$. Kemudian contoh air dibawa ke Laboratorium Fakultas Pertanian Universitas Tadulako (Untad) untuk disaring dengan kertas saring yang telah diketahui berat keringnya. Kertas saring beserta endapannya kemudian dikeringkan dalam oven sampai beratnya konstan, kemudian ditimbang berat tanah tererosi dengan menggunakan timbangan analitik. Setelah selesai pengambilan sampel, ember dibersihkan untuk pengamatan berikutnya. Pola sistem pertanian konservasi dengan agroforestri dianalisis secara deskriptif dan analisis citra. Teknik analisis citra digunakan untuk memperoleh informasi lokasi atau letak pola-pola tanaman agroforestri yang nantinya akan ditampilkan di dalam peta. 
Tahapan yang dilakukan dalam teknik analisis citra: (1) pengelolahan citra Google Earth, proses ini bertujuan untuk memperbaiki kualitas citra agar mudah diinterpretasi; (2) Georeferensi pada citra dari Google Earth berfungsi untuk mereduksi distorsi geometrik dari objek permukaan bumi yang ada pada citra yang diakibatkan kelengkungan permukaan bumi dan beberapa faktor lain, seperti variasi tinggi satelit, ketegakan satelit dan kecepatannya, sehingga posisi spasial dari suatu area pada citra sesuai dengan posisi sebenarnya di lapangan. Kegiatan ini juga sering dinamakan rektifikasi, yaitu memperbaiki kemencengan, rotasi dan perspektif citra sehingga orientasi, proyeksi dan anotasinya sesuai dengan yang ada pada peta (Danoedoro, 2012); (3) pemotongan citra/ cropping citra dari Google Earth berfungsi untuk membatasi daerah penelitian dan mengurangi besar file citra; (4) survei lapangan yang bertujuan untuk memperoleh kebenaran langsung suatu objek di lapangan menggunakan GPS agar posisi/koordinat UTM pola agroforestri yang ada di lapangan dapat diketahui dengan mudah. Total erosi pada setiap pola agroforestri dihitung dengan persamaan (1) yang dikemukakan oleh (Monde, 2008).

$$
E p=(S g \times V g)+(R c x S c) L p \text {. }
$$

Keterangan:

Erosi dalam satu hektar dihitung dengan rumus $\mathrm{E}=10000\left(\mathrm{~m}^{2}\right) / \mathrm{luas}$ plot $\left(\mathrm{m}^{2}\right)$ x Ep $(\mathrm{g})$, dengan Ep = erosi plot (g/plot),

Sg = kadar sedimen dalam sampel bak penampung ( $\mathrm{g} / \mathrm{l})$;

$\mathrm{Vg}=$ volume aliran permukaan yang masuk bak penampung (l);

Rc = volume aliran permukaan yang masuk ke cerigen (l);

$\mathrm{Sc}=$ kadar sedimen dalam sampel ember penampungan (g/l);

$\mathrm{Lp}$ = banyaknya lubang pembuangan, dan $\mathrm{E}=\operatorname{erosi}(\mathrm{g} / \mathrm{ha})$.

\section{Hasil dan Pembahasan}

\section{Pola Agroforestri dengan Pemanfaatan Citra Google Earth}

Penggunaan Google Earth dalam penelitian ini yaitu untuk mencari posisi koordinat sistem pertanian konservasi pola tanaman agroforestri yang dikembangkan oleh masyarakat di Sub-DAS Wuno. Secara umum sistem pertanian konservasi pola agroforestri di Sub-DAS Wuno (Gambar 1) lebih dominan menerapkan pola agroforestri random mixture sebesar 1.212 ha dan yang paling kecil luasannya adalah pola alternative rows sebesar 10 ha, pola agroforestri random mixture yaitu pola tanam acak, artinya antara tanaman pertanian dan pohon ditanam tidak teratur.

Umumnya masyarakat di Sub-DAS Wuno berprofesi sebagai petani agroforestri dengan pola yang diterapkan adalah berupa kebun pekarangan, kebun campuran dan tanaman kehutanan. Karakteristik pola tanam agroforestri sangat bergantung pada pemilik lahan serta karakteristik lahannya. Lahan pertanian agroforestri yang ada di Sub-DAS Wuno sejak dahulu telah banyak ditumbuhi kemiri dan aren. Seiring dengan waktu pengetahuan mereka semakin berkembang dan mulai melakukan penanaman jenis tanaman lainnya di sekitar kemiri dan aren lebih intensif, atau lebih dikenal dengan pola agroforestri. Hal ini sejalan dengan pendapat Irwanto (2007) yang menyatakan bahwa dengan pola tanam agroforestri dapat dikatakan bahwa masyarakat sudah dapat memanfaatkan lahan yang kosong (lahan yang kurang produktif) untuk menanam tanaman jenis lainnya seperti tanaman palawija dan tahunan.

Agroforestri dapat berperan dalam mempertahankan fungsi hidrologi DAS, yaitu dengan tutupan lahan oleh tutupan pohon berupa hutan alami atau permudaan alam, pohon yang dibudidayakan, dan pohon sebagai tanaman pagar yang dapat memengaruhi aliran air di antaranya berupa: (1) intersepsi air hujan, selama hujan, dan tajuk pohon yang dapat menyimpan air hujan pada permukaan daun dan batang akan mengalami evaporasi 
sebelum jatuh ke tanah, (2) daya pukul air hujan, yaitu vegetasi dan lapisan serasah untuk melindungi pukulan langsung air hujan yang dapat menyebabkan pemadatan tanah, dan (3) drainase lanskap (bentang lahan) yang dipengaruhi oleh beberapa faktor di antaranya relief permukaan tanah yang memungkinkan air tinggal di permukaan tanah lebih lama sehingga dapat memicu terjadinya aliran cepat air tanah (van Noordwijk et al., 2005).

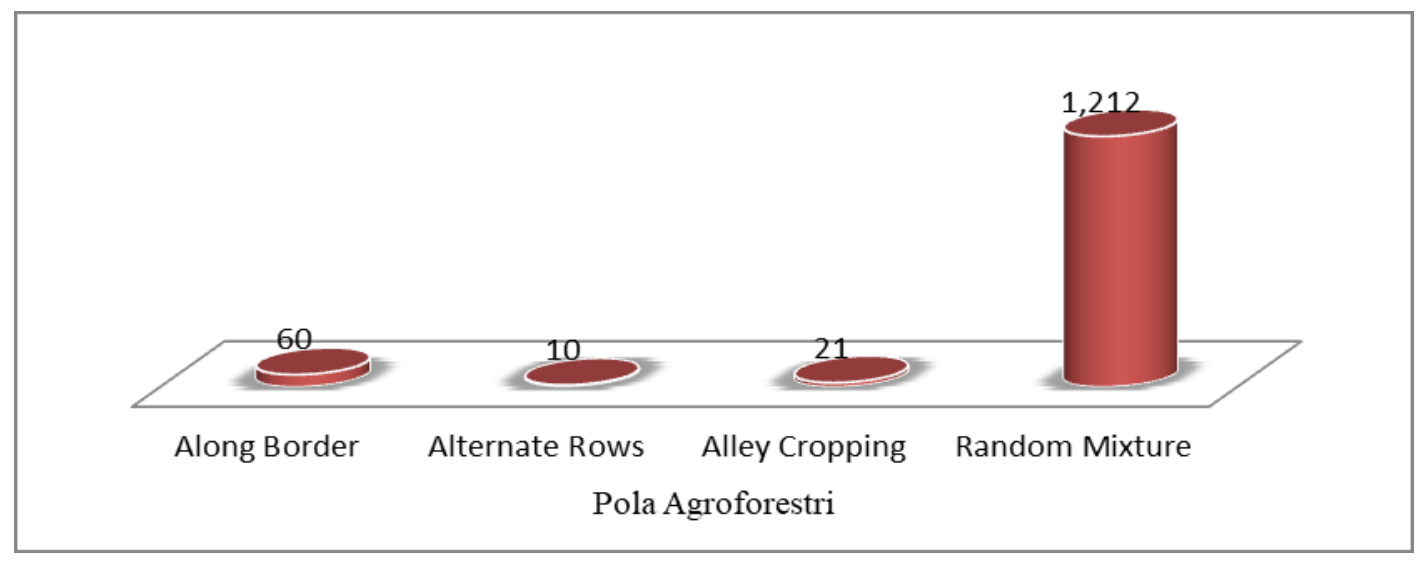

Sumber: Analisis Penulis, 2018

\section{Gambar 1. Luas Sistem Pertanian Konservasi Pola Agroforestri di Sub-DAS Wuno}

Secara lebih jelas, detail spot pola agroforestri dan sebarannya di Sub-DAS Wuno ditampilkan pada Gambar 2. Pola agroforestri trees along border (TAB) seperti yang ditunjukkan pada Gambar 2 merupakan kombinasi antara tanaman semusim dan tanaman kehutanan yang dapat berfungsi sebagai penyangga baik secara ekonomi maupun lingkungan. Hasil ground check menunjukkan bahwa pola penanaman pohon di bagian pinggir lahan dan tanaman pertanian berbeda di bagian tengah. Pohon-pohon yang ditanam mengelilingi lahan biasanya difungsikan sebagai pagar ataupun pembatas lahan. Tanaman perkebunan khususnya kakao juga digunakan petani untuk mengisi bagian tengah pola pohon pembatas. Kakao ditanam secara sistematis dan sebagai pembatasnya adalah tanaman berkayu. Tanaman pembatas yang menyusun pola pohon pembatas sebagian besar disusun oleh jenis tanaman kehutanan jenis pinus (Pinus merkusir).

Pola agroforestri alternate rows seperti yang ditampilkan pada Gambar 2, yaitu model penanaman model agroforestri yang menempatkan pohon dan tanaman pertanian secara berselang-seling. Pola agroforestri ini mungkin dilakukan pada tanah yang relatif datar. Pola baris merupakan bentuk penyusunan pola tanam setiap satu baris tanaman berkayu diselingi dengan tanaman pertanian secara bergantian. Model penyusunan tanaman pada pola baris terlihat sistematis. Tanaman pertanian yang ditanam adalah jagung dan ketela, beberapa ada yang menanam pisang sebaris dengan tanaman berkayu. Tanaman berkayu yang ditanam adalah jenis-jenis tanaman perkebunan, yaitu kakao ( Theobroma cacao L.) dan kemiri (Aleurites moluccana L.).

Pola agroforestri alley cropping seperti yang ditampilkan pada Gambar 2, yaitu pola tanaman agroforestri yang menempatkan pohon di pinggir kanan dan kiri tanaman pertanian. Larikan pohon membujur ke timur/barat. Hal ini dimaksudkan agar tanaman mendapatkan cahaya matahari penuh di pagi maupun sore hari. Pola alley cropping sering disebut dengan bentuk lorong karena apabila dilihat dari ujung lahan menyerupai lorong goa. 


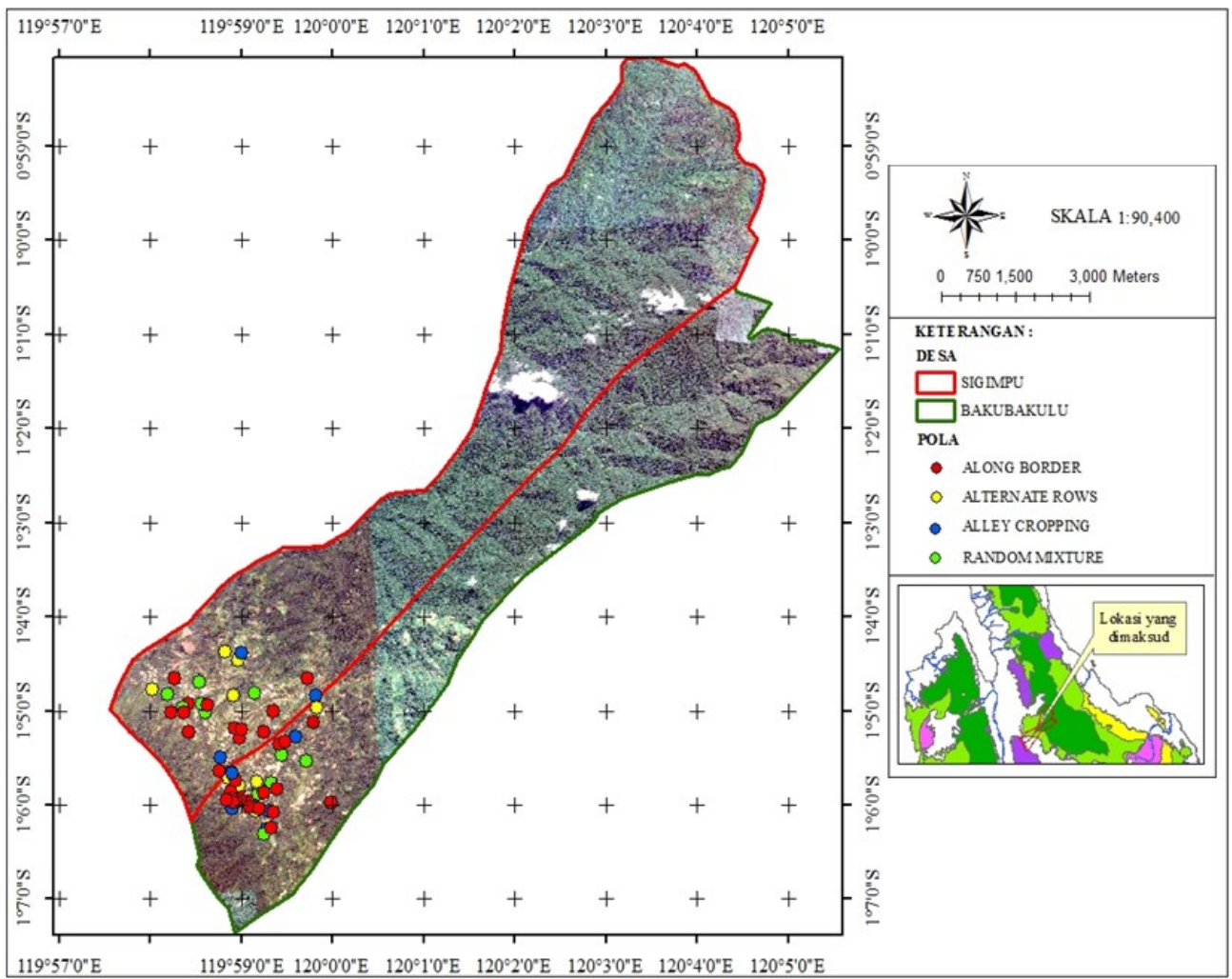

Sumber: Analisis Penulis, 2018

Gambar 2. Sebaran Pola Agroforestri di Sub-DAS Wuno

Pola agroforestri random mixture seperti yang ditampilkan pada Gambar 2, yaitu pola penanam acak, artinya antara tanaman pertanian dan pohon ditanam tidak teratur. Pola acak ini terbentuk karena tidak adanya perencanaan awal dalam menata letak tanaman. Penempatan tanaman berkayu pada suatu lahan terlihat tidak sistematis. Variasi pola campur adalah pada jenis penyusun, baik penyusun tanaman kehutanan, maupun tanaman pertanian. Tanaman pertanian pada pola campur ditanam pada sela-sela tanaman berkayu yaitu tanaman pisang (Musa paradisiaca L.). Tanaman berkayu yang mendominasi penyusunan pola campur adalah jenis-jenis tanaman kehutanan dan perkebunan, yaitu kemiri (Aleurites moluccana (L.) Willd.), nyatoh (Palaquium sp) dan aren (Arenga pinnata Merr.).

Pola agroforestri alternate rows, alley cropping, trees along border, random mixture tersebut tidak terlepas dari pemikiran pemilik lahan dan tingkat pengetahuan yang dimiliki. Selain itu, desakan kebutuhan akan bahan pangan menjadi pertimbangan mendasar terbentuknya sistem ini. Bagi masyarakat subsistem, kebutuhan pangan didapat dari lahan pertanian yang dimilikinya. Desakan kebutuhan ini mendorong terbentuknya ruang yang dibutuhkan untuk tanaman pertanian lebih dominan daripada ruang yang dibutuhkan untuk kehutanan. 


\section{Erosi pada Pola Agroforestri}

Hasil penelitian menunjukkan bahwa erosi yang terjadi pada empat pola agroforestri yang paling tinggi adalah pola alley cropping sebesar 5,17 gram/ha dan yang terendah adalah pola agroforestri trees along border sebesar 0,47 gram/ha dari total curah hujan 493,6 mm (Tabel 1). Dari empat pola agroforestri tersebut, dalam rangka perbaikan lingkungan dan pembangunan wilayah, maka pola agroforestri trees along border lebih efektif dalam meminimalkan laju erosi dibandingkan dengan tiga pola lainnya. Umumnya trees along border lebih dominan dengan berbagai variasi tanaman tahunan dan terbukti dapat menekan laju erosi. Hal tersebut sejalan dengan pendapat Atmojo (2008) bahwa variasi tanaman tahunan dan tanaman pertanian akan mengurangi pengaruh pukulan butir hujan secara langsung ke permukaan tanah (terhindar dari rusaknya struktur tanah), melindungi daya transportasi aliran permukaan, menahan sedimen, meningkatkan pasokan air ke dalam tanah dan mengurangi evaporasi sehingga meningkatkan ketersedian air tanah, dan meningkatkan cadangan air di musim kemarau.

Tabel 1. Erosi pada Pola Agroforestri

\begin{tabular}{lcc}
\hline \multicolumn{1}{c}{ Pola Agroforestri } & $\begin{array}{c}\text { Curah } \\
\text { hujan }(\mathbf{m m})\end{array}$ & Erosi (g/ha) \\
\hline Trees along border & 493,6 & 0,47 \\
Alternate rows & 493,6 & 4,93 \\
Alley cropping & 493,6 & 5,17 \\
Random mixture & 493,6 & 0,78 \\
\hline
\end{tabular}

Tingginya erosi pola agroforestri alley cropping, karena tutupan lahannya dominan tanaman pertanian dan rendahnya bahan organik tanah. Hal tersebut didukung oleh penelitian yang dilakukan Nurmani, Monde, \& Rahman (2016) bahwa unsur organik cenderung memperbaiki struktur tanah dan bersifat meningkatkan permeabilitas tanah, kapasitas tampung air tanah, dan kesuburan tanah. Kumpulan unsur organik di atas permukaan tanah dapat menghambat kecepatan air limpasan dan dengan demikian menurunkan terjadinya erosi. Struktur tanah memengaruhi kapasitas infiltrasi tanah, yaitu struktur tanah granuler memiliki keporosan tanah yang tinggi sehingga akan meningkatkan kapasitas infiltrasi tanah. Permeabilitas memberikan pengaruh pada kemampuan tanah dalam meloloskan air, sedangkan tanah dengan permeabilitas tinggi menaikkan laju infiltrasi.

Erosi yang tinggi pada sistem pertanian konservasi di Sub-DAS Wuno, DAS Palu, sangat erat kaitannya dengan faktor perilaku petani yang mempercepat terjadinya erosi (Gambar 3). Pola agroforestri alley cropping dan trees along border (Tabel 1) bila dibandingkan dengan pola agroforestri Trees along border dan Random mixture erosi yang terjadi sangat besar, hal tersebut terjadi karena pengaruh tutupan lahan. Pengaruh faktor tutupan lahan terhadap tingkat limpasan permukaan maupun infiltrasi sangat erat kaitannya dengan keberadaan vegetasi yang berpengaruh secara langsung pada struktur tanah (porositas tanah, permeabilitas tanah), jenis serta ketebalan serasah dan kegiatan biologis tanah (Asdak, 2002; Braud, Vich, Zuluaga, Fornero, \& Pedrani, 2001).

Peran tutupan lahan pada suatu area resapan tidak hanya berhubungan dengan terbentuknya pori tanah namun berhubungan juga dengan perannya sebagai penahan permukaan tanah dari tumbukan air hujan. Air hujan setelah mencapai permukaan tanah akan mengalami peristiwa penghacuran agregat tanah, apabila tanah tersebut tidak tertutupi vegetasi. Vegetasi sangat berperan dalam meminimalisir terjadi aliran permukaan dan eros. Kondisi penutupan tanah sangat tergantung kepada vegetasi (jenis dan masa 
pertumbuhan, seresah), dan benda-benda lain (batuan, bongkahan tanah) maupun segala aktifitas yang terjadi di permukaan tanah tersebut (Budiastuti, 2009).

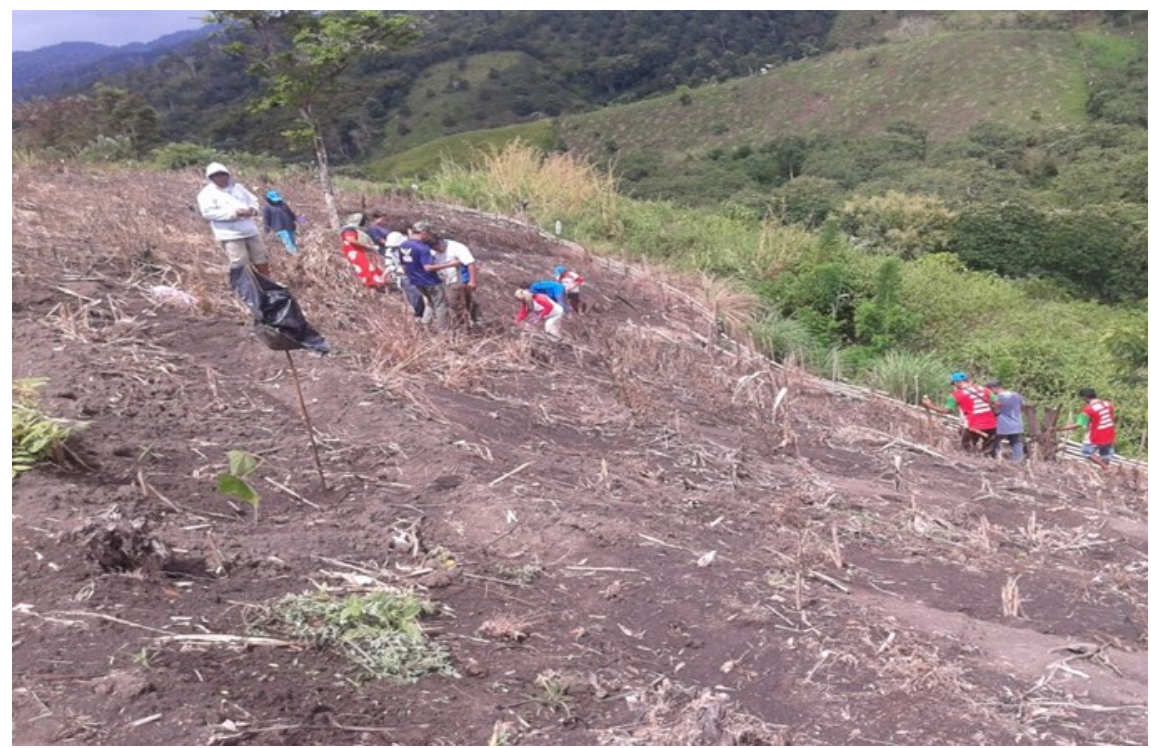

Sumber: Dokumentasi Observasi Lapangan, 2018

\section{Gambar 3. Perencanaan Sistem Pertanian Konservasi Pola Agroforestri di Sub DAS Wuno}

Sistem pertanian konservasi pola agroforestri dapat menurunkan aliran permukaan yang mengakibatkan erosi, sesuai dengan penelitian yang dilakukan Ngaji (2009). Konversi lahan tidak produktif (alang-alang dan lahan terbuka) menjadi sistem agroforestri yang akan mengurangi limpasan permukaan yang mengakibatkan erosi sebesar 43-64\%, sedangkan konversi menjadi hutan akan mengurangi limpasan permukaan sebesar $78-90 \%$. Ketika lahan tidak produktif dikonversi ke sistem agroforestri atau hutan, maka terjadi peningkatan aliran cepat tanah sekitar 1-7\% dari total curah hujan.

Pada pola agroforestri trees along border dan random mixture, tutupan kanopi lebih luas dan padat dibandingkan dengan pola agroforestri alley cropping dan alternate rows. Hal ini menyebabkan adanya perbedaan erosi yang terjadi. Tutupan kanopi merupakan suatu areal permukaan tanah yang dilindungi oleh vegetasi. Efektifitas tutupan kanopi dalam mengendalikan erosi sangat dipengaruhi oleh karakteristik hujan, jenis tanah dan juga karakteristik dari kanopi itu sendiri seperti jenis tanaman, tinggi tanaman dan struktur kanopi. Besarnya erosi dan aliran permukaan menurun secara eksponensial dengan semakin baiknya tutupan kanopi. Semakin banyak lahan yang ditutupi oleh vegetasi akan semakin baik dalam melindungi tanah dari proses erosi. Selain mampu mengendalikan erosi akibat hujan, tutupan kanopi juga dapat mengendalikan erosi yang disebabkan oleh angin dengan cara mengintersepsi angin, sebagai penahan angin dan juga memperlambat pergerakan angin (As-Syakur, 2011).

Struktur dari tutupan kanopi dari sistem pertanian konservasi pola agroforestri berfungsi sebagai pengendali besarnya energi kinetik hujan yang akan mengenai tanah yaitu luasan dan bentuk strata dari tutupan kanopi akan mempengaruhi besarnya intersepsi butiran hujan dan jumlah percikan air hujan. 


\section{Kesimpulan}

Sistem pertanian konservasi pola agroforestri di Sub-DAS Wuno terbukti dapat memberikan manfaat bagi pembanguan wilayah dan perbaikan lingkungan ekosistem DAS, terutama pada pola agroforestri trees along border dan random mixture. Tutupan kanopi pola agroforestri berpengaruh terhadap besarnya erosi yang terjadi di Sub-DAS Wuno, DAS Palu. Dalam rangka perbaikan lingkungan dan pembangunan wilayah, khususnya pola agroforestri, sebaiknya dikembangkan pola agroforestri trees along border karena lebih efektif dalam menekan erosi. Untuk lebih meningkatkan efektivitas dalam menekan laju erosi, dari empat pola agroforestri sebaiknya dipadukan konservasi secara mekanik dengan jalan pembuatan saluran pembuangan air, teras bangku dan bangunan teknik konservasi mekanik lainnya.

\section{Daftar Pustaka}

As-Syakur, A. R. (2011). Perubahan penggunaan lahan di Provinsi Bali. Ecotrophic: Jurnal Ilmu Lingkungan (Joumal of Environmental Science), 6(1), 1-7.

Asdak, C. (2002). Hidrologi dan pengelolaan daerah aliran sungai. Yogyakarta: Gadjah Mada University Press.

Atmojo, S. W. (2008). Peran agroforestri dalam menanggulangi banjir dan longsor DAS. In Disajikan dalam dalam Seminar Nasional Prndidikan Agroforestry Sebagai Strategi Menghadapi Pemanasan Global di Fakultas Pertanian.

Braud, I., Vich, A. I. J., Zuluaga, J., Fornero, L., \& Pedrani, A. (2001). Vegetation influence on runoff and sediment yield in the Andes region: Observation and modelling. Joumal of Hydrology, 254, 124-144. doi:10.1016/S0022-1694(01)00500-5.

Budiastuti, Mt. S. (2009). Hidrologi tapak lahan: Perubahan tutupan lahan dan tingkat resapan air. Sains Tanah (Journal of Soil Science and Agroclimatology), 6(1), 15-26. Retrieved from http://jurnal.fp.uns.ac.id/index.php/tanah/article/view/62.

Danoedoro, P. (2012). Pengantar penginderaan jauh digital. Yogyakarta: Penerbit Andi Yogyakarta.

Darmayanti, A. S. (2012). Beberapa sifat fisika kimia tanah yang berpengaruh terhadap model kecepatan infiltrasi pada tegakan mahoni, jabon, dan trembesi di Kebun Raya Purwodadi. Jumal Penelitian Hayati, 17(1), 185-191.

Daswir, D. (2010). Peran seraiwangi sebagai tanaman konservasi pada pertanaman kakao di lahan kritis. Buletin Littro, 21(2), 117-128.

Hairiah, K., Sardjono, M. A., \& Sabarnurdin, S. (2003). Pengantar agroforestri: Bahan ajaran agroforestri 1. Bogor: World Agroforestry Centre (ICRAF). Retrieved from www.worldagroforestry.org/sea/Publications/files/lecturenote/LN0001-04.pdf\%0A\%0A.

Liu, J., Liu, W., \& Zhu, K. (2018). Throughfall kinetic energy and its spatial characteristics under rubber-based agroforestry systems. Catena, 161,113-121. doi:10.1016/j.catena.2017.10.014.

Monde, A. (2008). Dinamika kualitas tanah, erosi, dan pendapatan petani akibat alih guna lahan hutan menjadi lahan pertanian dan kakao/agroforestri kakao di DAS Nopu, Sulawesi Tengah. Institut Pertanian Bogor. Retrieved from https://repository.ipb.ac.id/handle/123456789/3081.

Naharuddin, N. (2017). Komposisi dan struktur vegetasi dalam potensinya sebagai parameter hidrologi dan erosi. Jurnal Hutan Tropis, 5(2), 134-142. Retrieved from https://ppjp.ulm.ac.id/journal/index.php/jht/article/view/4367.

Ngaji, A. U. K. (2009). Pengaruh perubahan tutupan lahan terhadap kondisi hidrologis kawasan daerah aliran sungai Talau. 16(1), Partner, 51-55. Retrieved from http://jurnal.politanikoe.ac.id/index.php/jp/article/view/61.

Nuraida, N., Rachman, L. M., \& Baskoro, D. P. T. (2016). Analisis nilai konservasi tinggi aspek pengendali erosi dan sedimentasi (HCV 4.2) di DAS Ciliwung Hulu. Jumal Pengelolaan Sumberdaya Alam Dan Lingkungan, 6(2), 151-159. doi:10.19081/jpsl.6.2.151.

Nurmani, U., Monde, An., \& Rahman, A. (2016). Indikasi bahaya erosi (IBE) pada beberapa penggunaan lahan di Desa Malei Kecamatan Balaesang Tanjung Kabupaten Donggala. Jurnal Agrotekbis, 4(2), 186-194. 


\section{Sistem Pertanian Konservasi Pola Agroforestri dan Hubungannya dengan Tingkat Erosi ...}

Rahman, M. W., Purwanto, M. Y. J., \& Suprihatin, S. (2014). Status kualitas air dan upaya konservasi sumberdaya lahan di DAS Citarum Hulu, Kabupaten Bandung. Jurnal Pengelolaam Sumberdaya Alam Dan Lingkungan, 4(1), 24-34. doi:10.29244/jpsl.4.1.24.

Sardjono, M. A., Djogo, T., Arifin, H. S., \& Wijayanto, N. (2003). Klasifikasi dan pola kombinasi komponen agroforestri: Bahan ajaran agroforestri 2. Bogor: World Agroforestry Centre (ICRAF). Retrieved from https://www.worldagroforestry.org/region/sea/publications/download?dl=/lecturenote/LN000204.pdf\&pubID $=76$.

Sarminah, S., Karyati, K., Karmini, K., Simbolon, J., \& Tambunan, E. (2018). Rehabilitation and soil conservation of degraded land using sengon (Falcataria moluccana) and peanut (Arachis hypogaea) agroforestry system. Biodiversitas, 19(1), 222-228. doi:10.13057/biodiv/d190130.

Setyowati, D. L. (2008). Sifat fisik tanah dan kemampuan tanah meresapkan air pada lahan hutan, sawah, dan permukiman. Jurnal Geografi, 4(2), 114-128. Retrieved from https://journal.unnes.ac.id/nju/index.php/JG/article/view/103.

Syam, A. (2003). Dryland management sistem in upper watershed. Jurnal Penelitian Dan Pengembangan Pertanian, 22, 162-171.

Tunas, I. G. (2008). Pengaruh prosedur perkiraan laju erosi terhadap konsistensi nisbah pengangkutan sedimen. Jurnal SMARTek, 6(3), 135-143. $\quad$ Retrieved from http://jurnal.untad.ac.id/jurnal/index.php/SMARTEK/article/view/476.

van Noordwijk, M., Agus, F., Suprayogo, D., Hairiah, K., Pasya, G., Verbist, B., \& Farida, F. (2005). Peranan agroforestri dalam mempertahankan fungsi hidrologi daerah aliran sungai (DAS). In Dampak hidrologis hutan, agroforestri, dan pertanian lahan kering sebagai dasar pemberian imbalan kepada penghasil jasa lingkungan di Indonesiaidrologis hutan, agroforestri, dan pertanian lahan kering sebagai dasar pemberian imbalan kepada penghasil jasa (pp. 23-38). Bogor: ICRAF. Retrieved from http://www.worldagroforestry.org/publication/peranan-agroforestri-dalam-mempertahankan-fungsihidrologi-daerah-aliran-sungai-das. 